\title{
Open Doors and Clear Bound Aries: Mentorship in the Changing Context of Graduate Medical Education
}

\author{
Jennifer M. Charlesworth ${ }^{1,}$, Sarah Knudson ${ }^{2}$, Mary V. Seeman ${ }^{1,3}$ \\ ${ }^{1}$ Institute of Medical Science, University of Toronto, Toronto, Canada \\ ${ }^{2}$ St. Thomas More College, University of Saskatchewan, Saskatoon, Canada \\ ${ }^{3}$ Department of Psychiatry, University of Toronto, Toronto, Canada \\ *Corresponding author: charlesworth.jennifer@gmail.com
}

Received December 13, 2013; revised December 29, 2013; accepted January 20, 2013

\begin{abstract}
Effective mentorship can mean the difference between success and failure in any career. We set out to examine mentorship (the student-supervisor relationship) of graduate students in a Medical Faculty. Themes were extracted from taped and transcribed focus group data gathered at an intervention workshop held for students and supervisors of the Institute of Medical Science at the University of Toronto in November 2010. This was supplemented with 6 in-depth, semi-structured, 60 minute interviews with students and supervisors completed in spring 2012. Three important themes needed for effective mentorship were extracted: 1) on-going, frank, informal communication, 2) mutually understood, evolving boundaries that address needs of students and supervisors and 3) supportive independence for students permitting growth and development. In conclusion, graduate faculties must develop and implement policies that encourage mentorship-friendly environments in order to ensure faculty accountability to students while, at the same time, avoiding rigid, bureaucratic approaches to graduate supervision.
\end{abstract}

Keywords: Mentorship, Supervision, Graduate Education, Research, Academic Medicine, Thematic Analysis

\section{Introduction}

The difference between having and lacking a solid mentor early in one's career "can mean the difference between success and failure in any field" [1]. This is especially true in graduate school, and applies to graduate medical training, the context of this paper [2],[3].

We wanted to investigate how graduate medical research programmes, and graduate programmes more broadly, foster a "mentorship culture" [4]. By mentorship we mean a "helping relationship" centred around an experienced professional's transfer of knowledge and know how to a trainee in order to advance the junior professional's understanding and eventual achievement [5],[6].

Our particular interest was the graduate studentsupervisor relationship.

\section{Method}

The research described here was carried out at the Institute of Medical Science (IMS), University of Toronto, which boasts the largest graduate program at the university, which in turn is the largest research university in Canada. IMS has two streams of study: one for qualified medical doctors (clinician scientists), geared to provide rigorous research training in the clinical or basic sciences, and the second for academics with an interest in medical research that provides interdisciplinary, clinically oriented graduate training in the basic and clinical sciences. A range of collaborative programs is also available and the focus, at both the MSc and the PhD level, is on research training as opposed to course work.

In 2010, after obtaining signed consent from the participants (students and post-doctoral fellows) in medical research training, we audiotaped and transcribed an IMS workshop on the topic of student-supervisor relationships. Subsequently, between late 2011 and early 2012, we conducted in-depth, semi-structured interviews of approximately 60-minute duration with 6 students and 2 primary supervisors (who identified themselves as having a primary supervisory role). The interviewees signed informed consent and the interviews were transcribed. They focused on participants' general feelings about graduate supervision, their individual experiences and thoughts about challenges with supervision, the supervisory relationship and the nature of communication within this relationship.

The initial workshop began with a series of 14 vignettes courtesy of "The "Supervision Scenes" video and guidebook from The Centre for Teaching and Academic Growth, University of British Columbia, portraying common student-supervisor problems. This was followed by open discussion of topics such as the role of the supervisor and programme advisory committee, authorship, work hours and implementation of the IMS Student Oath (a promise to abide by ethical standards) [7]. 
Selection of students and faculty to subsequently interview was based on purposive sampling strategies with the goal of accurately representing the faculty and graduate student structure. We stopped at 6 as data saturation (when new information ceases to appear) had been reached. The transcripts of the workshop and of the 6 interviews were then subjected to thematic analysis by the method recommended by McCracken (1988) [8]. None of the quotations used in this paper identify the speakers, who were assured of confidentiality.

\section{Theme 1 Communication}

There was much discussion at the workshop about the frequency of communication between student and supervisor and the importance of clarity about the scope and expectations of the relationship. Beyond regular, formal or pre-planned meetings, both students and supervisors welcomed informal opportunities to discuss research, career planning and all other aspects of students' transition to independence. Whether face-to-face on campus, by phone, or virtually via technologies like email and Skype, relationships with an "open door" understanding that student and supervisor would be available for impromptu exchanges were considered in a positive light.

In interdisciplinary environments like IMS, where supervisors are frequently appointed to more than one department or research unit, and where many supervisors have clinical responsibilities, supervisors' diverse commitments can make for a richer sharing of knowledge and offering of networking opportunities between supervisor and student, but they can also contribute to time strain and encroach on chances for informal discussions that foster growth.

To ensure that opportunities for dialogue are not restricted to pre-planned or departmentally mandated gatherings such as laboratory meetings and committee meetings, effective mentors make themselves available to students in a flexible manner, as questions and issues arise. A graduate student contrasts such a mentor to other students' experiences:

"Well, my friends have profs whom they never speak to, they see once a month. I see [my supervisor] every day. [...] It's just even a hey, how are you, how's everything? How's the stuff coming along? If I'm not in the lab for four days because I'm writing, I'll call her and just say, What's going on, I'm in touch with these people, I'm making sure all this stuff is working out, how is everything? Life?" (Student)

While supervisors committed to ongoing, informal communication acknowledge the challenge of fitting it all in among multiple responsibilities, they also regard it as the basis of successfully developing a graduate student's career and note that up-front time investment tends to yield greater student independence in the long run:

"I think that, for the most part, students get a lot of time with me if they need it and want it [...] if somebody needs something, I try to be as responsive as possible." (Supervisor)

"Well, my colleagues are annoyed by [students' desire for ongoing communication] because it takes more time. But my idea is that giving proper instruction will help their development eventually. I don't have to work. They will work instead of me. That is my ideal goal for education." (Supervisor)

Student's and supervisor's research interests can diverge over time and the supervisor may not always be the best person to consult on specific problems. This need not, however, prevent the supervisor from facilitating his or her student interaction with other mentors. For instance, one student remarked that his supervisor was exemplary in her efforts to introduce him to colleagues and other valuable contacts at conferences:

"I'm surprised by the fact that when you attend talks, [she] will say this student of mine did this, this student of mine did this, and when you're at a conference and you're meeting people she's like this is my student, he's done this, this and this. You guys should talk. So it's really her trainees first and I can really see the evolution of my relationship in terms of writing with her." (Student)

As with many other interdisciplinary academic environments, IMS is geographically spread out-not only across a university campus, but also across the city of Toronto. The institute's success in exposing its students to cutting-edge research is undeniably attributable, in large part, to its research partnerships throughout the campus and city, and this, in turn, creates a climate ripe for good mentorship. At the same time, however, geographic dispersion demands that communication and coordination between supervisors and students be more deliberate and erodes the sense of academic community that is more easily fostered when members of a programme, college or institute who are in frequent contact with one another:

"All of my committee worked in different buildings around Toronto. [...] In my Master's [programme at a different university] I had a very different setup where it was a much more departmental feel, like smaller. Everyone was in the same place and I do think that that is better [when] there was a closer proximity between me and the committee members." (Student)

"I think that lack of informal interaction is also probably a lost opportunity or maybe not a loss of opportunity for formal stuff but there's a lost opportunity there on the part of the student for sort of informal discussion and informal mentorship about research and careers. [...] It's kind of an artificial community in some sense because it's so spread out." (Student)

Students can also veer off track more easily with infrequent informal communication, and correcting for such detours can be time- consuming and frustrating:

"When you are working alone and you are physically separated, you can kind of go off the path. It takes longer to realize that you are on the wrong path than if you were seeing [a supervisor or committee member] over coffee everyday or every other day. [...] I just think there were things that maybe could have been cut off sooner, could have been redirected sooner." (Student)

Frequent informal communication is important. This is illustrated by a senior Ph.D. student in IMS whose supervisor moved out of country toward the end of her programme, but who has managed to continue actively exchanging ideas with the student and giving her the 
benefit of his expertise by keeping lines of communication open. They often talk via Skype and email, a technological advance that can be harnessed to promote effective mentorship.

Technology — notably the Internet - has revolutionized the way in which students and supervisors communicate and collaborate. There is a symbiotic relationship between frequent, informal communication and technologically reliable educational contexts. The outcome of this symbiosis is that, despite hectic schedules and geographic dispersion, supervisor-student duos can use computermediated technology to maintain an "open door" of ongoing communication. This is particularly true of email exchanges:

"It's good because it can happen at any time; it can be 10:00 at night or 6:00 in the morning or noon and that's nice. You can send the e-mail off when you encounter a problem and you can leave it. You can just stop worrying about it whereas if you are trying to track someone down [in person] you don't let it go until you find them." (Student)

Relying on technology can, however, be a two-edged sword in the supervisor-student relationship. As one heavy e-mail user explained, communicating through technology has been overwhelmingly helpful, but not always without mishap:

"I don't know how many e-mails I have sent to [my advisor] but maybe 1000, maybe not thousands, but a lot. I think that only one or two were misunderstood, but it was not a serious case." (Student)

Another student noted that e-mail communication poses the danger of inviting more superficial "passing over" of complex concerns than face-to-face interaction, thereby hindering the in-depth exchanges that are a part of exemplary mentorship. For supervisors uninterested in or unmotivated to engage in detailed discussion or simply overwhelmed by other demands, e-mail can also provide an excuse for keeping input to a minimum.

"One of my concerns in hindsight is that it's much easier over a time-saving technology to hand-wave through a solution to a problem. If a paper is circulated and you provide a couple of short comments maybe you only read half of it or maybe you only read the abstract. You can be seen to be providing feedback without perhaps fulfilling that job to the fullest. Whereas, if you sit across from someone, it's much more difficult to sort of fake your way through that. Maybe [supervisors] like it because it's faster and easier but I'm not sure that it's always the best way to solve the problem." (Student)

Effective mentors, rather than hiding behind computermediated technologies and glossing over complicated issues, balance communication via time-saving technologies with in-person dialogue and are aware of the value and appropriateness of each:

"Feedback face-to-face is the best way; I believe that is the best way to teach them because when we do e-mailing, e-mail remains and so, sometimes, if I talk harshly, I don't want to bully them [by having it stay in print]. Also, the clinical situation is changing very quickly, so I think the best thing to memorize something really important is to [discuss] something that happened right after the incident. Right after the event is the most important moment for teaching." (Supervisor)

\section{Theme 2 Boundaries}

The supervisor-student relationship in graduate school not only plays a major role in shaping students' career trajectories but also impacts their self-esteem and sense of self as researchers and professionals. It is, as one IMS student described it, a "complex but evolving" partnership with the potential to endure well beyond a student's time in graduate school and evolve into a collegial or friendship relationship. Part of its complexity is due to its delicacy, given the unequal power dynamics of the relationship: students rely upon supervisors - to varying degrees - for guidance, access to resources (financial and otherwise), opportunities to publish and approval to advance through the milestones of their graduate programme. Supervisors, while generally in a position of greater authority vis-à-vis students, may also rely on graduate students for research assistance leading to publications, securing funds and developing reputations as effective teachers and scientists. Our interviewees openly attest to the problems and ambiguities, as well as the positive outcomes, that can arise:

"[My supervisor] and I have developed beyond a supervisory relationship, we became friends, and I think that's really important to me, but that did interfere with our ability to work together." (Student)

"[My supervisor] is very much like a mother figure. She knows exactly when to push me and when to be really hard on me. She can say things that can be really hurtful, but at the end of the day I know she wouldn't support me the way she does in every other aspect if she didn't care for me or want me to succeed." (Student)

Because of the delicacy and complex power dynamics, supervisor-student relationships need clearly defined boundaries. This means a clear understanding of each party's rights and responsibilities, the parameters being set through a two-way dialogue. Maintenance of a supervisory relationship's boundaries will assist in overcoming the numerous challenges that arise. IMS has implemented a student oath [8], designed to guide students through ethical quagmires. However, our data suggest that beyond the oath, frequent updates and knowledge dissemination are also required to ensure a complete and uniform understanding of ethical issues.

Drawing and maintaining clear supervisory boundaries is an important ethical and practical issue. In interdisciplinary environments, it is particularly important to engage in frank student-supervisor discussions about boundaries and expectations. As supervisors acknowledged, dialogue with students about relationship parameters and approaches to collaboration is crucial:

"Just my point of view is not enough and so I ask a medical student to share their own view. I think the kind of mutual sharing of [ideas and expectations] will help with the learning process for him or her. I also learn from him or her." (Supervisor)

Furthermore, since interdisciplinary programmes like IMS attract students from a variety of backgrounds and with varying professional goals, it is particularly important for students and supervisors to frankly discuss 
how they might tailor their relationship to appropriately prepare students for their intended career trajectory. Although a supervisor may feel (and express) disappointment when students decide to follow a career path other than the one the supervisor expected (for instance, a graduate student desiring a non-academic job after graduation), good mentorship implies flexibility. For instance, one supervisor explained that in cases of students wishing to veer away from research careers after graduation, she prefers redrawing supervisor-student research responsibilities in a way that will let the supervisor inherit or build on the student's research while freeing the student to pursue other goals.

The geographic dispersion characteristic of IMS and many academic environments can also make communication of expectations more difficult. In the case of the student whose supervisor moved out of the country but continued to actively supervise her graduate research, their relationship has weathered the transition not only because they have kept in frequent contact, but also because they were up-front about discussing how geographic changes would change relationship boundaries:

"Between [my supervisor] and the other committee members they discussed and figured out how to make it work. So, I felt that actually IMS was understanding and he was understanding and he is still invested and interested. So, I'm not stressed out at all." (Student)

More often, supervisors do not leave the country but change hospitals or departments or take on extra administrative responsibilities, all of which puts strains on the relationship with students. Busy supervisors have assistants who are put in charge of scheduling appointments and meetings with students; this places one more spatial and logistical hurdle between the supervisor and the student. Open discussions about boundaries - and ongoing efforts to adjust to boundary shifts - will do much to mitigate these challenges. Mentoring by more senior students or peer groups helps:

“At IMS there wasn't what I later found at [the college], which is an intellectual community who [...] knows how to have fun, but primarily I know everyone there is intellectual and I can have informed, interesting conversations. I've found that IMS lacks that culture." (Student)

\section{Theme 3 Independence}

Much as students want and require mentorship, they also need to develop a sense of independence that prepares them for a research career. Effective mentorship promotes independence in students. One student believed that communicating with his supervisor through computer-mediated technologies helped him retain a greater sense of independence, whereas prior experiences of intensive face-to-face collaboration with his supervisor had led to feelings of boundary erosion and a diminished sense of ownership over his research output. A relationship in which the student is perceived as independent can, however, be associated with a slow turnaround time for feedback on students' work. In the case of a student whose supervisor was promoted to a demanding administrative position and whose e-mail traffic increased significantly thereby, the promotion provoked considerable anxiety in the student-who anticipated a sharp drop availability on the part of the supervisor-and suggested the need for a revision of relationship roles and expectations:

"In my first year [of the new arrangement] I felt anxiety. I was worried as it was very difficult to engage him in terms of schedules [...] I think that overall the time is there, but I cannot control the time, right?" (Student)

Independence is valued by students but needs to evolve gradually. When it arrives too rapidly, it becomes a source of anxiety.

\section{DISCUSSION}

On the basis of our data, we agree with Brown and colleagues [2] that effective mentors perform the following functions: they support the mentee's transition to independence, they educate and encourage, they communicate empathy and genuineness, they expose the mentee to a variety of research methods and new opportunities, and they promote scholarly values and scientific integrity. There is evidence that effective graduate mentorship exerts a positive effect on students' socio-emotional satisfaction, productivity and overall career development [9],[10]. We also agree that many academic environments such as IMS are complex, geographically dispersed and pressured to produce topnotch research in the face of increasing resource scarcity - namely funding, time and support staff [11][13]. These challenges are further compounded by the shift to computer-mediated communication (CMC) between supervisors and students - $a$ trend identified a decade ago as altering traditional supervisory models [14] This trend has not yet plateaued [15]-[17].

Three themes have emerged from our data: the need for frequent informal communication between student and mentor, the need to framing the supervisory relationship in a clear and flexible manner and renegotiating it when necessary, and the need to work toward the student's independence but in a gradual manner. We suggest that issues pertaining to effective, on-going communication and supervisor-student relationship expectations need to be verbalized, documented (preferably as departmental policies) and monitored.

While these recommendations emerged though our study of IMS students and faculty, it generalizes to other contexts in graduate education. We recommend continuing study of the student-supervisor relationship [4]

\section{CONCLUSION}

Both students and supervisors bear the responsibility of initiating and maintaining a relationship that fosters growth. Beyond that, graduate departments need to develop mechanisms and implement policies that encourage mentorship-friendly environments that ensure supervisors' accountability to students. Our data does not support, however, rigid, bureaucratic approaches to graduate supervision. To the contrary, we share the view 
of other researchers [1],[5] that the supervisor-student relationship - and the mentorship that grows out of this relationship - evolves organically and may need to be individualized to meet specific needs. As faculty and graduate students in graduate programmes face continued pressure to perform and thrive in environments where resources (including, most pertinent to our discussion, time) are limited, these issues grow in importance.

\section{Acknowledgement}

No funding was provided for this study authors did the work pro-bono. The authors would like to acknowledge The Centre for Teaching and Academic Growth, University of British Columbia who provided the 'Supervisor Scenes' video which was the foundation of the pilot workshop and this study.

\section{Competing Interests}

The authors have no competing interests to declare.

\section{Abbreviations}

CMC - computer-mediated communication

IMS - Institute of Medical Science, University of Toronto

\section{References}

[1] Lee, A., Dennis, C., and Campbell, P., "Nature's guide for mentors," Nature, 447. 791-797, June 2007.

[2] Brown, R., Daly, B., and Leong, F., "Mentoring in Research: A Developmental Approach," Professional Psychology: Research and Practice, 40 (3). 306-313, June 2009.

[3] Gurr, G., 'Negotiating the 'Rackety Bridge' - a Dynamic Model of Aligning Supervisory Style with Research Student
Development," Higher Education Research \& Development, 20 (1). 81-92, May 2001.

[4] Editorial. "Mentoring matters," Nature Cell Biology, 12 (2). 101, Feb. 2010.

[5] Collins, P., "The Interpersonal Vicissitudes of Mentorship: An Exploratory Study of the Field Supervisor-Student Relationship," The Clinical Supervisor, 11 (1). 121-135, 1993.

[6] Hicks, R. and McCracken, J., "Mentoring vs. Coaching-Do You Know the Difference?" Physician Executive Journal. 71-73, July/August 2009.

[7] Davis, K., Seeman, M.V, Chapman, J. and Rotstein, O., "A graduate student oath," Science, 320 (5883). 1587-1588, June 2008.

[8] McCracken, G., The Long Interview, Qualitative Research Methods Series 13, Sage, Beverley Hills, CA, 1988.

[9] Styles, I. and Radloff, A., "The Synergistic Thesis: student and supervisor perspectives," Journal of Further and Higher Education, 25 (1). 97-106, 2001.

[10] Tenenbaum, H., Crosby, F., and Gilner, M., "Mentoring Relationships in Graduate School," Journal of Vocational Behavior, 59. 326-341, Dec. 2001.

[11] Deem, R. and Brehony, K., "Doctoral Students' Access to Research Cultures-are some more unequal than others?" Studies in Higher Education, 25 (2). 149-165, June 2000.

[12] Leder, G., "Higher degree research supervision: a question of balance," Australian Universities' Review, 2. 5-8, 1995.

[13] Malfroy, J., "Doctoral supervision, workplace research and changing pedagogic practices," Higher Education Research \& Development, 24 (2). 165-178, 2005.

[14] Stacey, E. and Fountain, W., "Student and Supervisor Perspectives in a Computer-Mediated Research Relationship," in Meeting at the Crossroads: Proceedings of the 18th Annual Conference of the Australian Society for Computers in Learning in Tertiary Education, ASCILITE, 519-528. Dec. 2001.

[15] Millson, M. and Wilemon, D., "Technology enabling innovation in online graduate management education," International Journal of Innovation and Technology Management, 5 (4). 401-421, Dec. 2008.

[16] Rudestam, K., "Distributed education and the role of online learning in training professional psychologists," Professional Psychology: Research and Practice, 35 (4). 427-432, Aug. 2004.

[17] Tisdell, E., Carver, M., Corrigan, P., Nash, J., Nelson, M., Royer, M., Strom-Mackey, R. and O'Connor, M., "Cohort Learning Online in Graduate Higher Education: Constructing Knowledge in Cyber Community," Educational Technology \& Society 7 (1). 115-127, Jan. 2004 